\title{
Should public health interventions aimed at reducing childhood overweight and obesity be gender-focused?
}

\author{
Aline Simen-Kapeu ${ }^{\dagger}$ and Paul J Veugelers* ${ }^{*}$
}

\begin{abstract}
Background: Overweight in childhood is a major public health concern that calls for immediate preventative action. An increasing number of reports suggest that gender specific approaches to prevention may be more effective. However, there is a paucity of information to guide gender-sensitive health promotion and population health interventions for the prevention of overweight in childhood. In the present study, we sought to determine genderdifferentials in overweight and underlying behaviors, nutrition and physical activity, among pre-adolescents in Alberta, Canada, to inform the discussion on gender-focused interventions for chronic disease prevention.

Methods: In 2008, we surveyed 3421 grade five students and their parents of 148 randomly selected schools. Students completed the Harvard food frequency questionnaire, questions on physical activities, and had their height and weight measured. Parents completed questions on socio-economic background and child's lifestyle. We applied multilevel regression methods to assess gender differentials in overweight, nutrition and physical activity.

Results: Overall, the prevalence of overweight was slightly higher among boys (29.1\%) than girls (27.9\%) with more pronounced differences in towns and urban geographies. Boys reported to be much more physically active relative to girls $(\mathrm{OR}=2.12,95 \% \mathrm{Cl}: 1.73-2.60)$. Diets of boys, relative to those of girls, reportedly constituted more fat and were less likely to meet the recommendation of 6 daily servings of vegetables and fruits $(\mathrm{OR}=0.81,95 \% \mathrm{Cl}$ : $0.71-0.93)$.

Conclusion: Our findings confirm the existence of gender differences in physical activity and nutrition, and support gender-focused health promotion whereby priority is given to physical activity among girls and to healthy eating among boys.
\end{abstract}

\section{Background}

The prevention of childhood overweight and obesity is a public health priority in developed countries [1]. Unhealthy diets and physical inactivity are the established determinants of the rising prevalence of overweight and obesity in childhood [2,3]. Research of these determinants has become increasingly important due to the increasing recognition of the need for preventative actions. For example, childhood overweight has been reported to vary between geographies, with higher prevalence rates observed in rural areas relative to urban areas in most developed countries, suggesting that priority for

\footnotetext{
* Correspondence: paul.veugelers@ualberta.ca

1 School of Public Health, University of Alberta, Edmonton, Canada + Contributed equally

Full list of author information is available at the end of the article
}

programs should be given to children and youth residing in rural areas [4].

The etiology of overweight and obesity among girls and boys may be different due to biology (sex differences) as well as society and culture (gender differences) $[5,6]$. Various studies have examined the importance of gender for overweight and obesity in childhood [5,7-9], some reported no gender-difference $[10,11]$, some reported higher overweight prevalence among boys [12,13] whereas other reported higher overweight rates among girls $[14,15]$. Some recent studies showed gender differentials with respect to the behavioral determinants of overweight including calorie intake [16-19] and physical and sedentary activities [20-23]. Girls were shown to pay more attention to foods as a way to influence health and to meet nutritional recommendations, and boys report-

(C) 2010 Simen-Kapeu and Veugelers; licensee BioMed Central Ltd. This is an Open Access article distributed under the terms of the CreBFoMed Central ative Commons Attribution License (http://creativecommons.org/licenses/by/2.0), which permits unrestricted use, distribution, and reproduction in any medium, provided the original work is properly cited. 
edly ate more fast foods $[16,17]$. Adolescent girls reported less physical activity, fewer active role models, more barriers and less perceived benefits to physical activity relative to boys [20,22].

Consideration of gender differentials in public health interventions may have positive effects on their effectiveness [24]. Gender mainstreaming, an approach where no considerations is given to gender specific needs in the development and implementation of policies, programmes and projects, may therefore be less effective and miss the aim of gender equity. In fact, it has been suggested that gender mainstreaming in health promotion may contribute to gender-differences in health behaviors [5]. Even though knowledge of gender-differences in childhood is increasingly available, more research is important to providing guidance to program planners and public health decision makers with a mandate in chronic disease prevention. With the scarcity of gender studies in the field of childhood overweight, we sought to assess gender-differentials in overweight, physical activity, nutrition and health behaviors among pre-adolescent children in the province of Alberta, Canada, to bring more insights into the discussion on gender-focused interventions for chronic disease prevention.

\section{Methods}

\section{The Survey}

The Raising Healthy Eating and Active Living Kids in Alberta survey http://www.REALKidsAlberta.ca aims to evaluate a comprehensive initiative by Alberta Health and Wellness to promote healthy body weights among children and youth through surveys in 2008 and 2010 among grade five students who are primarily 10 or 11 years of age. The present study reports on the 2008 observations. The study employed a one-stage stratified random sampling design. The sampling frame include all 1505 schools with grade five students, with the exception of private schools (4.7\% of all Alberta children attend such schools), francophone schools $(0.6 \%)$, on-reserve federal schools (2.0\%), charter schools $(1.7 \%)$, and colony schools $(0.8 \%)$ [25]. Schools were stratified into three geographies: 1) urban: Calgary and Edmonton; 2) towns: other municipalities with more than 40,000 residents; and 3) rural: municipalities with less than 40,000 residents. Schools were randomly selected within each of these strata to achieve a balanced number of students in each stratum. Of the 184 invited schools, 148 (80.4\%) participated in the study. These schools were attended by 5594 grade five students who received an envelope with a parent survey and consent form to take home. Of the 3758 (67.2\%) students that returned completed consent form to school, 3645 (97.0\%) had received parental consent to participate. Of these students, 3407 were present when evaluation assistants visited the school to conduct the survey, 6 stu- dents declined to participate, and 20 absent students completed and mailed their surveys, resulting in 3421 participating students (61.2\% of total student population in those schools). These students completed the Harvard Food Frequency Questionnaire for Youth and Adolescents (FFQ) which is suitable for grade five students [26]. Students further completed a short survey on activities and behaviors, and had their heights and weights measured.

\section{Measurements}

Standing height was measured by trained evaluation assistants to the nearest 0.1 centimeter without shoes using stadiometers and body weight to the nearest 0.1 kilogram on calibrated digital scales. Body mass index was calculated by dividing weight (in kilograms) by height (in meters) squared. Overweight (including obesity) and obesity were defined using the body mass index cut-off points for children and youth by the International Obesity Task Force [27].

Parents and students responded to activity questions on: a) travel to and from school; b) time spent to get to and from school; c) frequency of child's activities outside of school hours; d) activities at morning and lunch recess in the past seven days; and e) frequency of involvement in sports and physical activities in the past seven days. These questions, totaling 29 items, were by large adopted from the Physical Activity Questionnaire for Children (PAQ-C) which has previously been validated and demonstrated high reliability [28]. The 29 items were the basis of a composite score ranging from 1 to 6 . Students with a score exceeding 3 were classified as 'physically active'. Students also provided answers on the frequency $(<3$ times/week or $\geq 3$ times/week) during which they were engaged in physical activities with a coach ("sports with coach"), without a coach ("sports without coach"), or with parents ("sports with parents") out of school hours. Parents answered questions on the number of hours $(\leq 2$ hours/day or $>2$ hours/day) that their child spent playing videos games, watching television and using the computer out of school hours ("screen time"). These questions have been previously validated and were adopted from the National Longitudinal Survey of Children and Youth [29].

Based on students' responses to the FFQ and nutrient information from Canadian food tables [30], we calculated the nutrient intake for each of the participating students. Specifically, we calculated percentage of energy in their diets originating from dietary fat, and calculated whether students complied with Canadian guidelines of 6 servings of vegetables and fruits per day [31]. The questionnaires for students further included 6 questions on types of foods they would eat or purchase (see table 1). 
Table 1: Characteristics of grade five students in Alberta, Canada

\begin{tabular}{|c|c|c|c|c|}
\hline & Prevalence & Boys & Girls & $p$ value \\
\hline \multicolumn{5}{|l|}{ Body weight status } \\
\hline Overweight & 28.54 & 29.13 & 27.98 & 0.50 \\
\hline Obese & 6.9 & 7.57 & 6.27 & 0.16 \\
\hline \multicolumn{5}{|l|}{ Parental educational attainment } \\
\hline Secondary graduation or less & 26.54 & 25.72 & 27.30 & \\
\hline Postsecondary or college diploma & 39.91 & 38.44 & 41.29 & \\
\hline University degree & 33.55 & 35.84 & 31.41 & 0.04 \\
\hline \multicolumn{5}{|l|}{ Household income } \\
\hline$<\$ 50,000$ & 23.37 & 23.79 & 22.97 & \\
\hline$\$ 50,001-\$ 75,000$ & 17.48 & 16.46 & 18.45 & \\
\hline$\$ 75,001-\$ 100,000$ & 22.19 & 22.51 & 21.89 & \\
\hline$>\$ 100,000$ & 36.96 & 37.24 & 36.69 & 0.73 \\
\hline \multicolumn{5}{|l|}{ Geographic location } \\
\hline Urban & 47.33 & 47.85 & 46.84 & \\
\hline Small town & 16.21 & 15.27 & 17.11 & \\
\hline Rural & 36.45 & 36.88 & 36.05 & 0.33 \\
\hline \multicolumn{5}{|l|}{ Physical activity } \\
\hline Being physically active (PAQ C score $>3$ ) & 26.04 & 31.97 & 20.43 & $<0.01$ \\
\hline Engaged in sport activities without coach $\geq 3$ times/week & 38.56 & 44.47 & 33.0 & $<0.01$ \\
\hline Engaged in sport activities with coach $\geq 3$ times/week & 15.72 & 18.14 & 13.46 & $<0.01$ \\
\hline Engaged in sport activities with parents $\geq 3$ times/week & 8.09 & 7.47 & 8.68 & 0.24 \\
\hline Screen time $\geq 2$ hours/day & 16.27 & 16.34 & 16.20 & 0.90 \\
\hline \multicolumn{5}{|l|}{ Nutrition } \\
\hline Buy soup, sandwiches or burritos at school $\geq 3$ times/week & 12.68 & 13.62 & 11.79 & 0.05 \\
\hline $\begin{array}{l}\text { Buy snacks like donuts, candy, chocolate bars and chips at } \\
\text { school } \geq 3 \text { times/week }\end{array}$ & 8.78 & 9.22 & 8.37 & 0.42 \\
\hline Eat food from fast food restaurant $\geq 3$ times/week & 39.73 & 42.31 & 37.31 & $<0.01$ \\
\hline Eat convenient food $\geq 3$ times/week & 43.48 & 45.71 & 41.37 & 0.02 \\
\hline Eat fried food at home $\geq 3$ times/week & 54.4 & 56.30 & 52.61 & 0.05 \\
\hline Eat fried food away from home $\geq 3$ times/week & 41.4 & 41.63 & 40.69 & 0.61 \\
\hline Mean \% energy from fat $\dagger$ & 27.56 & 27.81 & 27.32 & $<0.01$ \\
\hline Consumption of $\geq 6$ servings of vegetables and fruits/day & 26.68 & 24.72 & 28.53 & 0.02 \\
\hline
\end{tabular}

*Significant gender differences $(P<0.05)$ : $X^{2}$-tests were used for all outcomes except for '\% energy from fat' where a t-tests was used. All estimated were weighted to represent population prevalence.

† Percentage of dietary energy originating from dietary fat

Finally, the questionnaire completed by parents provided information on household income $(\leq \$ 50,000$; $\$ 50,001-\$ 75,000 ; \$ 75,001-\$ 100,000$ and $>\$ 100,000)$ and parental education (secondary school or less, community college and graduate university).

\section{Statistical analysis}

We applied multilevel logistic regression methods to assess gender differences in overweight, physical activity and nutrition while acknowledging the nested structure of the data whereby student observations nest within those of schools. All analyses were weighted to account for the design effect such that estimates apply to the grade five student population of Alberta. We adjusted for the confounding potential of parental education attainment, household income and residency. Analyses pertaining to dietary outcomes ('having $30 \%$ or more of dietary energy from dietary fat' and 'eating 6 or more 
servings of vegetables and fruits daily') were further adjusted for calorie intake as is recommended for FFQ data [32]. Missing values for parental education attainment, household income were treated as separate covariate categories. Stata Version 10 (Stata Corp, TX, USA) was used to perform the statistical analyses. This study, including data collection and parental informed consent forms, was approved by the Health Research Ethics Board of the University of Alberta.

\section{Results}

Our study included comparable participation of boys (48.6\%) and girls (51.4\%). The prevalence of overweight, including obesity, was higher among boys (29.1\%) than girls $(27.9 \%)$ although the difference was not statistically significant (Table 1). Among grade five students in Alberta, $26.0 \%$ was reportedly physically active. This was statistically significant differed for boys (32.0\%) and girls (20.4\%). Relative to girls, boys reported to engage more in sports with a coach (18.1\%) and in sports without a coach (44.5\%). No substantial differences were observed in the reporting of screen time (Table 1 ).

Boys consumed an estimated 1955 kilocalories per day and girls 1859 kilocalories per day. Table 1 shows that, relative to girls, boys had reportedly more energy from dietary fat and were less likely to meet the recommendation of 6 or more servings of vegetables and fruits per day.

Table 2 depicts the probability of boys, relative to girls, to be overweight, to be physically active and to eat healthy. When adjusting for parental educational attainment and household income, boys residing in towns were estimated to be $40 \%$ more likely to be overweight than girls (table 2 : $\mathrm{OR}=1.40)$. Relative to girls, boys reported to be more physically active $(\mathrm{OR}=2.12)$. With respect to physical activity, relative similar estimates were observed in urban areas $(\mathrm{OR}=2.10,95 \% \mathrm{CI}: 1.50-2.94)$, towns (OR $=2.48,95 \% \mathrm{CI}: 1.62-3.81)$ and rural areas $(\mathrm{OR}=2.00,95 \%$ CI: 1.49-2.68).

Relative to girls, boys were also more likely to report to eat food from a fast food restaurant (Table 2). Boys' diets, relative to those of girls, were more likely to have $30 \%$ or more of its energy to be from dietary fat. This gender differential was most pronounced in towns $(\mathrm{OR}=1.85,95 \%$ CI: 1.05-3.27). Boys, relative to girls, were less likely to meet the recommendation of 6 or more servings of vegetables and fruit per day (Table 2).

\section{Discussion}

In the present study we revealed gender-differences in physical activity and nutrition behaviors, the established causes of overweight. Girls reported to be less engaged in physical activities whereas boys reported unhealthier diets. Gender frameworks are not only important to our understanding of the determinants of health, but also for the development of effective health promotion programs [33]. Our results support the development of genderfocused health promotion programs as a strategy to reduce the burden of overweight and consequent chronic diseases.

\section{Gender and overweight}

We reported a slightly higher overweight prevalence among boys than girls. This observation is consistent with other Canadian and US studies that reported slightly lower prevalence of overweight among girls [11,34-37]. When focusing on specific geographies, we found that boys residing in towns were substantially more likely to be overweight as compared to girls. This reinforces the need to considering geographic discrepancies in addition to gender-focused approaches in the development of preventive strategies.

\section{Gender and health behaviors}

Various studies have shown that boys engaged more in physical activity than girls [38-40]. Physical activity counterbalances excess energy intake and the risk for overweight. This risk seems to be particularly present in rural schools and calls for programs to promote physical activity, particularly among girls during their transition from childhood to adolescence and adulthood, as longitudinal studies have shown a drop in activity levels during these years [5]. Specifically, a review of the literature suggested annual declines in physical activity of up to $2.7 \%$ among boys and 7.4\% among girls between the ages of 10-17 years [5].

Our study population constitutes grade five students who are primarily 10 or 11 years old and primarily preadolescent. Adolescence is a period of physical, psychosocial, cognitive, and emotional change that may be linked to physical maturity and may affect physical activity behaviors [41]. Thomson et al. [42] demonstrated that gender differences in physical activity diminished when aligned on maturational age, suggesting that sexual maturation may be intricately involved in the adolescent decline in physical activity. As girls mature approximately 2 years before boys [43], relative more girls than boys are expected to have entered sexual maturation in our study population. This may have contributed to the higher physical activity levels among boys relative to girls observed in this study. A US-based study suggested that early-maturing girls are twice as likely to be obese compared with early-maturing boys [44]. If this were to apply to our study participants, we should anticipate changing gender differentials in overweight in the year to come.

We observed gender-difference in dietary intake and eating behaviors that parallel observations in the relatively few studies that focused on gender and nutrition among children and adolescents $[4,34,36,45,46]$. We 
Table 2: Probability of being overweight or engaging in physical activity and nutrition behaviors of boys relative to girls

\begin{tabular}{|c|c|c|c|c|}
\hline & \multicolumn{2}{|c|}{ unadjusted } & \multicolumn{2}{|c|}{ adjusted } \\
\hline & OR & $95 \% \mathrm{Cl}$ & OR & $95 \% \mathrm{Cl}$ \\
\hline \multicolumn{5}{|l|}{ Overweight } \\
\hline In urban areas & 1.15 & $0.85-1.58$ & 1.18 & $0.85-1.64$ \\
\hline In towns & 1.38 & $1.03-1.34$ & 1.40 & $1.05-1.86$ \\
\hline In rural areas & 0.81 & $0.64-1.02$ & 0.82 & $0.65-1.03$ \\
\hline \multicolumn{5}{|l|}{ Physical activity } \\
\hline Being physically active (PAQ C score $>3$ ) & 2.09 & $1.71-2.55$ & 2.12 & $1.73-2.60$ \\
\hline $\begin{array}{l}\text { Engaged in sport activities without coach } \\
\geq 3 \text { times/week }\end{array}$ & 1.65 & $1.40-1.95$ & 1.68 & $1.42-1.98$ \\
\hline $\begin{array}{l}\text { Engaged in sport activities with coach } \geq 3 \\
\text { times/week }\end{array}$ & 1.47 & $1.15-1.86$ & 1.45 & $1.14-1.84$ \\
\hline $\begin{array}{l}\text { Engaged in sport activities with parents } \geq \\
3 \text { times/week }\end{array}$ & 0.84 & $0.67-1.06$ & 0.86 & $0.65-1.09$ \\
\hline Screen time $\geq 2$ hours/day & 1.01 & $0.81-1.25$ & 1.02 & $0.83-1.26$ \\
\hline \multicolumn{5}{|l|}{ Nutrition } \\
\hline $\begin{array}{l}\text { Buy soup, sandwiches or burritos at } \\
\text { school } \geq 3 \text { times/week }\end{array}$ & 1.28 & $1.00-1.66$ & 1.27 & $1.00-1.63$ \\
\hline $\begin{array}{l}\text { Buy snacks like donuts, candy, chocolate } \\
\text { bars and chips at school } \geq 3 \text { times/week }\end{array}$ & 1.11 & $0.83-1.47$ & 1.10 & $0.82-1.46$ \\
\hline $\begin{array}{l}\text { Eat food from fast food restaurant } \geq 3 \\
\text { times/week }\end{array}$ & 1.22 & $1.05-1.42$ & 1.22 & $1.05-1.43$ \\
\hline Eat convenient food $\geq 3$ times/week & 1.19 & $1.00-1.41$ & 1.20 & $1.01-1.42$ \\
\hline Eat fried food at home $\geq 3$ times/week & 1.17 & $0.98-1.40$ & 1.18 & $1.00-1.41$ \\
\hline $\begin{array}{l}\text { Eat fried food away from home } \geq 3 \text { times/ } \\
\text { week }\end{array}$ & 1.03 & $0.86-1.24$ & 1.04 & $0.86-1.25$ \\
\hline$\%$ energy from fat exceeds $30 \% \dagger$ & 1.63 & $1.16-2.29$ & 1.68 & $1.19-2.35$ \\
\hline $\begin{array}{l}\text { Consumption of } \geq 6 \text { servings of } \\
\text { vegetables and fruits/day }\end{array}$ & 0.81 & $0.71-0.93$ & 0.82 & $0.71-0.96$ \\
\hline
\end{tabular}

* Odds ratio (OR) 95\% confidence interval $(\mathrm{Cl})$. Adjusted risk estimates were adjusted for household income, parental education and residency. '\% energy from fat exceeds $30 \%$ ' and 'Consumption of $\geq 6$ servings of vegetables and fruits/day' were further adjusted for calorie intake.

† \% energy from fat exceeds $30 \%$ : represents the probability that more that $30 \%$ of dietary energy originating from dietary fat

observed higher calorie intakes among boys relative to girls, which is consistent with another Canadian study [4] and the fact that energy requirements among boys are slightly higher than among girls [37], though are inconsistent with studies reporting an absence in gender difference in children's energy intake [45,47]. The limited number of regarding gender comparisons in the literature likely reflects the challenge of collecting and analyzing dietary information among children.

\section{The need for gender-focused interventions}

Differences in overweight and health behaviors between boys and girls may result from differences in biology (sex differences), from differences assumed to be due to soci- ety or culture (gender differences), or a combination of the two $[6,48]$. With respect to health in general, there is support that integrating gender considerations into interventions will improve their effectiveness [24], though it is acknowledged that these gender considerations are often difficult to translate into health promotion and preventive programs [49]. In the Canadian public health care system, patient care absorbs the far majority of health sector resources, with less than $3 \%$ of health spending allocated for resources towards health promotion and primary prevention [50]. Therefore it is of utmost importance to invest these limited resources in effective preventive activities [51]. The lack of translation of knowledge about gender differentials in health and health 
behaviors into health promotion interventions may lead to a weakened potential for success and herewith inefficient use of resources [52]. Thus, studies into gender differences are important to increase our understanding of mechanisms of behavioral change to allow optimizing health promotion and interventions [53]. The present study contributes to this understanding for the prevention of childhood overweight and obesity. The results reinforce the needs for gender-focused health promotion and provide direction on how to deliver that.

Strengths of the present study include its large representative sample, measured heights and weights and its response rate that is considered high for school-based research. A further limitation relates to the cross-sectional design that necessitates caution with respect to interpretations related to directionality and causality. We had used the body mass index cut-off values by the International Obesity Task Force to define overweight and obesity [27]. These are increasingly established and some studies showed that they provided similar definitions for overweight though more conservative estimates for obesity [54-57].

Self report is prone to error. As in other studies, in the present study this may have lead to an over-reporting of "structured" activities and sport activities [41]. The use of objective measures of physical activity (e.g. pedometers) would have permitted us to more accurately estimate physical activity levels of students, although it is acknowledged that the use of such devices may be logistically and financially challenging in large population studies. The limitations of self report also apply to the assessment of dietary intake, although the Harvard Food Frequency Questionnaire for Youth and Adolescents is a extensively validated and used instrument [58]. Studies have shown that FFQ tend to underestimate energy intake when compared with measured energy intake $[59,60]$.

\section{Conclusions}

To conclude, this study highlights gender-differences in physical activity and nutrition behaviors, the underlying causes of overweight, in a large representative sample of Canadian preadolescent children. The results add to our understanding of the importance of gender in primary prevention of chronic disease. While overall gender-differences in overweight prevalence are relative small, gender-differences in health behavior are apparent and will affect the development of eating and activity habits if not intervened upon. Recognizing gender inequalities may allow for the development of more effective health promotion strategies. Without such gender considerations in health promotion, gender inequalities may in fact enhance. Where internationally considerable work is underway to integrate gender perspectives into preventative policies, the present study identified for a Canadian setting that physical activity among girls and healthy eating among boys are priority areas.

\section{Competing interests}

The authors declare that they have no competing interests.

\section{Authors' contributions}

ASK conducted the statistical analysis and literature review, and drafted the manuscript. PJV is the principal investigator, advised on the analytic approaches and assisted in the manuscript writing. Both authors read and approved the final version.

\section{Acknowledgements}

We thank all of the grade five students, parents and schools for their participation in the REAL Kids Alberta evaluation. We thank all the research assistants and regional health promotion coordinators for the execution of the data collection, Connie Lu and Dr. Stefan Kuhle for data management and validation. This research was funded through a contract with Alberta Health and Wellness and through a Canada Research Chair in Population Health and Alberta Heritage Foundation for Medical Research Health Scholarship to Dr Paul J. Veugelers. All interpretations and opinions in the present study are those of the authors.

\section{Author Details}

School of Public Health, University of Alberta, Edmonton, Canada

Received: 4 December 2009 Accepted: 14 June 2010

Published: 14 June 2010

\section{References}

1. Lobstein T, Baur LA, Uauy R: Obesity in children and young people: a crisis in public health. Obes Rev 2004, 5(Suppl 1):4-104.

2. Shields M: Overweight and obesity among children and youth. Health Rep 2006, 17:27-42.

3. Raine KD: Determinants of healthy eating in Canada: an overview and synthesis. Can J Public Health 2005, 96(Suppl 3):S8-15.

4. Veugelers PJ, Fitzgerald AL: Prevalence of and risk factors for childhood overweight and obesity. Can Med Ass J 2005, 173:607-613.

5. Sweeting HN: Gendered dimensions of obesity in childhood and adolescence. Nutr J 2008, 14:7:1.

6. Krieger N: Genders, sexes, and health: what are the connections - and why does it matter? Int J Epidemio/ 2003, 32:652-657.

7. Skelton JA, Cook SR, Auinger P, Klein JD, Barlow SE: Prevalence and trends of severe obesity among US children and adolescents. Acad Pediatr 2009, 9:322-329.

8. Munakata H, Sei M, Ewis AA, Umeno M, Sato Y, Nakano T, Sakamoto K, Yoshida Y, Onishi C, Nakahori Y: rediction of Japanese children at risk for complications of childhood obesity: gender differences for intervention approaches. J Med Invest 2010, 57:62-68.

9. Wisniewski AB, Chernausek SD: Gender in childhood obesity: family environment, hormones, and genes. Gend Med 2009, 6(Suppl 1):76-85. Review

10. Tremblay MS, Katzmarzyk PT, Willms JD: Temporal trends in overweight and obesity in Canada, 1981-1996. Int J Obes Relat Metab Disord 2002, 26:538-543.

11. Baskin ML, Ard J, Franklin F, Allison DB: Prevalence of obesity in the United States. Obes Rev 2005, 6:5-7.

12. Watkins DC, Murray LJ, McCarron P, Boreham CA, Cran GW, Young IS, McGartland C, Robson PJ, Savage JM: Ten-year trends for fatness in Northern Irish adolescents: the Young Hearts Projects--repeat crosssectional study. Int J Obes (Lond) 2005, 29:579-585

13. Xie B, Chou CP, Spruijt-Metz D, Reynolds K, Clark F, Palmer PH, Gallaher P, Sun P, Guo Q, Johnson CA: Socio-demographic and economic correlates of overweight status in Chinese adolescents. Am J Health Behav 2007, 31:339-352.

14. Salazar-Martinez E, Allen B, Fernandez-Ortega C, Torres-Mejia G, Galal O, Lazcano-Ponce E: Overweight and obesity status among adolescents from Mexico and Egypt. Arch Med Res 2006, 37:535-542.

15. Bénéfice E, Garnier D, Simondon KB, Malina RM: Relationship between stunting in infancy and growth and fat distribution during adolescence in Senegalese girls. Eur J Clin Nutr 2001, 55:50-58. 
16. Lorson BA, Melgar-Quinonez HR, Taylor CA: Correlates of fruit and vegetable intakes in US children. J Am Diet Ass 2009, 109:474-478.

17. Galloway T: Gender differences in growth and nutrition in a sample of rural Ontario schoolchildren. Am J Hum Biol 2007, 19:774-788.

18. Caine-Bish NL, Scheule B: Gender differences in food preferences of school-aged children and adolescents. J Sch Health 2009, 79:532-540.

19. Al Sabbah H, Vereecken C, Kolsteren P, Abdeen Z, Maes L: Food habits and physical activity patterns among Palestinian adolescents: findings from the national study of Palestinian schoolchildren (HBSCWBG2004). Public Health Nutr 2007, 10:739-46.

20. Irving HM, Adlaf EM, Allison KR, Paglia A, Dwyer JJ, Goodman J: Trends in vigorous physical activity participation among Ontario adolescents, 1997-2001. Can J Public Health 2003, 94:272-274

21. Kirchengast S, Marosi A: Gender differences in body composition, physical activity, eating behavior and body image among normal weight adolescents--an evolutionary approach. Coll Antropol 2008, 32:1079-86.

22. Hoelscher DM, Barroso C, Springer A, Castrucci B, Kelder SH: Prevalence of self-reported activity and sedentary behaviors among 4th-, 8th-, and 11th-grade Texas public school children: the school physical activity and nutrition study. J Phys Act Health 2009, 6:535-547.

23. De Cocker K, Ottevaere C, Sjöström M, Moreno LA, Wärnberg J, Valtueña J, Manios Y, Dietrich S, Mauro B, Artero EG, Molnár D, Hagströmer M, Ruiz JR, Sarri K, Kafatos A, Gottrand F, De Henauw S, Maes L, De Bourdeaudhuij I: Self-reported physical activity in European adolescents: results from the HELENA (Healthy Lifestyle in Europe by Nutrition in Adolescence) study. Public Health Nutr 2010. in press

24. Brown T, Summerbell C: Systematic review of school-based interventions that focus on changing dietary intake and physical activity levels to prevent childhood obesity: an update to the obesity guidance produced by the National Institute for Health and Clinical Excellence. Obes Rev 2009, 10:110-141.

25. Alberta Education: Student population by grade, school and authority, Alberta 2006/2007 school year. [http://education.alberta.ca/apps/ eireports/pdf files/eis1004 2007/eis1004 2007.pdf]. Last accessed November 15, 2007

26. Rockett HR, Wolf AM, Colditz GA: Development and reproducibility of a food frequency questionnaire to assess diets of older children and adolescents. J Am Diet Assoc 1995, 95:336-40.

27. Cole TJ, Bellizzi MC, Flegal KM, Dietz WH: Establishing a standard definition for child overweight and obesity worldwide: international survey. BMJ 2000, 320:1240-1243.

28. Crocker PRE, Bailey DA, Faulkner RA, Kowalski KC, McGrath R: Measuring general levels of physical activity: Preliminary evidence for the Physical Activity Questionnaire for Older Children. Med Sci Sports Exerc 1997, 29:1344-1349.

29. Statistics Canada: The National Longitudinal Survey among Children and Youth (NSLCY). [http://www.statcan.gc.ca/imdb-bmdi/4450eng.htm]. Last accessed October 20, 2009

30. Health Canada: Canadian Nutrient File (CNF). 2007 [http://www.hcsc.gc.ca/fn-an/nutrition/fiche-nutri-data/index-eng.php]. Last accessed September 2009

31. Government of Canada: Canadian Food Guide. [http://www.hcsc.gc.ca/fn-an/alt formats/hpfb-dgpsa/pdf/food-guide-aliment/ print eatwell bienmang-eng.pdf]. Last accessed September 2009

32. Willett W: Nutritional Epidemiology. 2nd edition. New York: Oxford University Press; 1998

33. Keleher $\mathrm{H}$ : Why build a health promotion evidence base about gender? Health Promot Int 2004, 19:277-279.

34. Tremblay MS, Willms JD: Secular trends in the body mass index of Canadian children. Can Med Ass J 2000, 163:1429-1433.

35. Hanning RM, Woodruff SJ, Lambraki I, Jessup L, Driezen P, Murphy CC Nutrient intakes and food consumption patterns among Ontario students in grades six, seven, and eight. Can J Public Health 2007, 98:12-16

36. Hedley AA, Ogden CL, Johnson CL, Carroll MD, Curtin LR, Flegal KM: Prevalence of overweight and obesity among US children, adolescents, and adults, 1999-2002. JAMA 2004, 291:2847-2850.

37. Galloway T: Gender differences in growth and nutrition in a sample of rural Ontario schoolchildren. Am J Hum Biol 2007, 19:774-788.

38. Botton J, Heude B, Kettaneh A, Borys JM, Lommez A, Bresson JL, Ducimetiere P, Charles MA, FLVS Study Group: Cardiovascular risk factor levels and their relationships with overweight and fat distribution in children: the Fleurbaix Laventie Ville Santé II study. Metabolism 2007, 56:614-622.

39. Sherar LB, Esliger DW, Baxter-Jones AD, Tremblay MS: Age and gender differences in youth physical activity: does physical maturity matter? Med Sci Sports Exerc 2007, 39:830-835.

40. Storey KE, Forbes LE, Fraser SN, Spence JC, Plotnikoff RC, Raine KD, Hanning RM, McCargar LJ: Diet quality, nutrition and physical activity among adolescents: the Web-SPAN (Web-Survey of Physical Activity and Nutrition) project. Public Health Nutr 2009, 12:2009-2017.

41. Sallis JF, Saelens BE: Assessment of physical activity by self-report: status, limitations, and future directions. Res Q Exerc Sport 2000, 71(2 Suppl):S1-14. Review

42. Thomson AM, Baxter-Jones AD, Mirwald RL, Bailey DA: Comparison of physical activity in male and female children: does maturation matter? Med Sci Sports Exerc 2005, 37:1902-1908.

43. Malina RM, Eisenmann JC, Cumming SP, Ribeiro B, Aroso J: Maturityassociated variation in the growth and functional capacities of youth football (soccer) players 13-15 years. Eur J App/ Physiol 2004, 91:555-562.

44. Wang Y: Is obesity associated with early sexual maturation? A comparison of the association in American boys versus girls. Pediatrics 2002, 110:903-910.

45. Champagne $\mathrm{CM}$, Bogle $\mathrm{ML}$, Karge $\mathrm{WH}$ : Using national dietary data to measure dietary changes. Public Health Nutr 2002, 5:985.

46. Moffat T, Galloway T, Latham J: Stature and adiposity among children in contrasting neighborhoods in the city of Hamilton, Ontario, Canada. Am J Hum Biol 2005, 17:355-367.

47. Cooke L, Grant M: Support for evidence-based practice. Semin Onco Nurs 2002, 18:71-78

48. Bird CE, Rieker PP: Gender matters: an integrated model for understanding men's and women's health. Soc Sci Med 1999, 48:745-755

49. Ostlin P: Gender perspective on socio-economic inequalities in Health In Reducing inequalities in Health Edited by: Mackenbach J and Bakker M. London, Routledge; 2002:25-49.

50. Hylton J: Improving Health Status through Intersectorial cooperation. Muttart Foundation, Edmonton, Canada; 2003.

51. Ostlin P, Eckermann E, Mishra US, Nkowane M, Wallstam E: Gender and health promotion: a multisectoral policy approach. Health Promot Int 2006, 21:25-35.

52. Thomas $\mathrm{H}$ : Obesity prevention programs for children and youth: why are their results so modest? Health Educ Res 2006, 21:783-795.

53. Kremers SP, de Bruijn GJ, Droomers M, van Lenthe F, Brug J: Moderators of environmental intervention effects on diet and activity in youth. Am J Prev Med 2007, 32:163-172.

54. Shields M, Tremblay MS: Canadian childhood obesity estimates based on WHO, IOTF and CDC cut-points. Int J Pediatr Obes 2010, 5(3):265-73.

55. Edwards J, Evans J, Brown AD: Using routine growth data to determine overweight and obesity prevalence estimates in preschool children in the Capital Health Region of Alberta. Can J Public Health 2008, 99:91-94.

56. Wang Y, Wang JQ: A comparison of international references for the assessment of child and adolescent overweight and obesity in different populations. Eur J Clin Nutr 2002, 56:973-982

57. Kain J, Uauy R, Vio F, Albala C: Trends in overweight and obesity prevalence in Chilean children: comparison of three definitions. Eur $\mathrm{J}$ Clin Nutr 2002, 56:200-204.

58. Rockett HR, Breitenbach M, Frazier AL, Witschi J, Wolf AM, Field AE, Colditz $\mathrm{GA}$ : Validation of a youth/adolescent food frequency questionnaire. Prev Med 1997, 26:808-816.

59. Schaefer EJ, Augustin JL, Schaefer MM, Rasmussen H, Ordovas JM, Dallal GE, Dwyer JT: Lack of efficacy of a food-frequency questionnaire in assessing dietary macronutrient intakes in subjects consuming diets of known composition. Am J Clin Nutr 2000, 71:746-51.

60. Paul DR, Rhodes DG, Kramer M, Baer DJ, Rumpler WV: Validation of a food frequency questionnaire by direct measurement of habitual ad libitum food intake. Am J Epidemiol 2005, 162:806-814.

\section{Pre-publication history}

The pre-publication history for this paper can be accessed here: http://www.biomedcentral.com/1471-2458/10/340/prepub

doi: 10.1186/1471-2458-10-340

Cite this article as: Simen-Kapeu and Veugelers, Should public health interventions aimed at reducing childhood overweight and obesity be genderfocused? BMC Public Health 2010, 10:340 